\title{
Empirical Study on the Empowerment of Families Raising Children with Severe Motor and Intellectual Disabilities in Japan: The Association with Positive Feelings towards Child Rearing
}

\author{
Hiroshi Fujioka1, Rie Wakimizu², Ryuta Tanaka3, Tatsuyuki Ohto3, Atsushi Ieshima4, \\ Akira Yoneyama ${ }^{5}$, Kiyoko Kamibeppu ${ }^{6 *}$ \\ ${ }^{1}$ Department of Nursing, Faculty of Health Sciences, Tsukuba International University, Tsuchiura-Shi, Japan \\ ${ }^{2}$ Department of Child Health Care Nursing, Division of Health Innovation and Nursing, Faculty of Medicine, \\ University of Tsukuba, Tsukuba-Shi, Japan \\ ${ }^{3}$ Department of Child Health, Graduate School of Comprehensive Human Sciences, University of Tsukuba, \\ Tsukuba-Shi, Japan \\ ${ }^{4}$ Aiseikai Kinen Ibaraki Welfare \& Medical Center, Mito-Shi, Japan \\ ${ }^{5}$ National Rehabilitation Center for Children with Disabilities, Itabashi-Ku, Japan \\ ${ }^{6}$ Department of Family Nursing, School of Health Sciences and Nursing, Graduate School of Medicine, The \\ University of Tokyo, Bunkyo-Ku, Japan \\ Email: "kkamibeppu-tky@umin.ac.jp
}

Received 22 November 2015; accepted 26 December 2015; published 29 December 2015

Copyright (C) 2015 by authors and Scientific Research Publishing Inc.

This work is licensed under the Creative Commons Attribution International License (CC BY).

http://creativecommons.org/licenses/by/4.0/

cc) (i)

Open Access

\section{Abstract}

Background: "Children with severe motor and intellectual disabilities" refers to children with markedly limited activity due to severe overlapping of physical and intellectual disabilities. The physical and mental burden placed on families raising severely disabled children, particularly the primary caregivers, is great in home settings. For families to effectively utilize services and overcome child rearing problems, the families themselves need the "strength" to cooperate with others for the purpose of raising a severely disabled child. The ultimate goal of family support is to enable such families to achieve satisfaction and self-growth in child rearing. Methods: We used a questionnaire to survey 75 primary caregivers to empirically elucidate the empowerment and positive feelings towards child rearing of families raising children with severe motor and intellectual disabilities and the related factors. The $t$-test and Spearman's rank correlation coefficient

\footnotetext{
${ }^{*}$ Corresponding author.
}

How to cite this paper: Fujioka, H., et al. (2015) Empirical Study on the Empowerment of Families Raising Children with Severe Motor and Intellectual Disabilities in Japan: The Association with Positive Feelings towards Child Rearing. Health, 7, 1725-1740. http://dx.doi.org/10.4236/health.2015.712188 
were used to examine the association with bivariates. A multiple regression analysis was conducted for empowerment and positive feelings. Results: Results revealed that life events, livelihood, awareness of social support and the child's sleep problems were factors related to empowerment. Of these, awareness of social support from outside of the family was found to contribute the most to empowerment. Furthermore, improvement and maintenance of positive feelings towards child rearing reaffirmed the existence of empowerment in addition to reducing negative feelings towards child rearing and ensuring social support. Conclusions: Raising children with severe motor and intellectual disabilities requires specialist knowledge and skills. Support from professionals to empower the entire family is therefore important in order to strengthen positive feelings towards child rearing.

\section{Keywords}

Children with Severe Motor and Intellectual Disabilities, Family, Empowerment, Positive Feelings towards Child Rearing

\section{Introduction}

"Children with severe motor and intellectual disabilities" (SMID) is a term defined with reference to Japan's unique legislation and refers to "children with markedly limited activity due to severe overlapping of physical and intellectual disabilities" [1]. Globally, SMID is synonymous with "children with profound multiple disabilities," i.e. children who cannot use their hands and arms by themselves due to an IQ of less than 20 [2].

In Japan, approximately $70 \%$ of the estimated 40,000 severely disabled children live at home [1]. The physical and mental burden placed on the families raising severely disabled children, particularly the primary caregivers, is great in home settings [3] [4]. Factors that most influence the stress of families with disabled children include developmental problems of the child, health problems and difficulties with care [5]. Children with severe disabilities have markedly delayed development and low spare physical capacity, which makes them susceptible to complications when they are ill and leads them to require diverse and highly individualized care. This is why the stress of families with severely disabled children is very serious [6]. Social and economic problems have also been pointed out such as the financial hardship faced when family members have to quit their jobs in order to care for the child [6].

For families to effectively utilize services and overcome child rearing problems, the quantity and quality of services not only need to be enhanced, but families themselves also need the "strength" to cooperate with others for the purpose of raising a severely disabled child. Globally, services have changed from a model in which professionals are superior to a "family-oriented" service model in which the wishes of the parents are prioritized in cooperation between parents and professionals [7]. The strength of families to cooperate and get actively involved in various service organizations and communities, i.e. empowerment, is therefore an important indicator in family support [8]. The ultimate goal of family support is to enable families themselves to achieve satisfaction and self-growth in child rearing.

This study was designed to empirically elucidate the empowerment and positive feelings towards child rearing of families raising severely disabled children in Japan and the related factors.

\section{Methods}

\subsection{Operational Definition: Empowerment}

In this study, empowerment was defined as "the state or ability of families to cooperate with elements outside of their living scope by controlling their life for the purpose of raising a severely disabled child" with reference to definitions in previous studies [9] [10].

\subsection{Subjects}

Subjects comprised primary caregivers raising a severely disabled child at home. The inclusion criteria were as 
follows: aged 20 years or older; able to answer a questionnaire (good physical and mental state and good language proficiency); aware that they are the primary caregiver of the child; and caring for a "child with SMID" that is aged 5 to 18 years and has marked difficulty with everyday communication and is unable to maintain a standing position alone.

Care recipients were primarily restricted to school age children because families with children aged less than 5 years have only recently received a diagnosis and were assumed to be emotionally unstable. Moreover, the circumstances of children over 18 years of age were assumed to become more individualized as the child and family aged.

\subsection{Procedure}

The investigators asked primary caregivers (subjects) of severely disabled children who regularly visited one of three facilities (university hospitals and rehabilitation facilities for severely disabled children; hereinafter, research cooperation facilities) in the Tokyo metropolitan area on an outpatient basis to answer an anonymous self-administered questionnaire. Subjects were first given an explanation of the outline of this study using a briefing document. The attending physicians at the research cooperation facilities then selected subjects based on the inclusion criteria.

In addition to the briefing document, subjects were also handed a questionnaire, a 500-yen gratuity in the form of a bookstore gift card, and a return envelope. Subjects who agreed to cooperate in this research answered the questionnaire and returned it to the investigators in the enclosed return envelope. Returning the questionnaire was considered to indicate consent. The study period was from May 2012 to January 2013.

\subsection{The Questionnaire}

The following items were included in the questionnaire.

\subsubsection{Empowerment}

We used the Japanese version of the Family Empowerment Scale (FES) [11]. The original FES [9] was developed as a scale to measure the empowerment of caregivers of children with emotional and developmental disabilities and is the most versatile empowerment scale in the world [12]. The areas of child rearing in which caregivers are involved are divided into three domains: family (caregivers themselves), service system and community/political. The family domain primarily examines the internal awareness and beliefs of the caregiver themselves as well as the knowledge and abilities that they possess. The service system domain examines cooperation with service providers (professionals) when receiving services. The community/political domain examines cooperation with politicians and government personnel/staff to build a better system of services. The family domain is comprised of 12 items, the service system domain 12 items, and the community/political domain 10 items (total 34 items). Each item is rated with a 5-point scale (1 to 5 points). A higher score indicates a higher level of empowerment. Cronbach's alpha in this study was 0.88 for family, 0.87 for the service system and 0.83 for community/political.

\subsubsection{Attributes of the Children with SMID}

The following information was collected regarding the attributes of the severely disabled children. Items were created based on sex, age, disability onset, time of definitive diagnosis, time at which home care was started (home period), possession of a physical disability certificate and childcare handbook, activities of daily living, physical and mental function, problematic behavior or habits (hurting others or themselves, harassing those around them), sleep problems, and required care (score for profoundly severely disabled children) [13]. Respiratory, dietary and other forms of care were scored and a total score of 25 points or more indicated a profoundly severely disabled child, while a score of 10 to 24 points indicated a quasi-profoundly severely disabled child. The questionnaire also collected information about services used, including the location of the facility and the time required to visit each facility.

\subsubsection{Attributes of the Primary Caregivers (Subjects Themselves) and Their Families}

The following information was collected regarding the attributes of the family (including the subjects themselves): age, relationship to the child, marital status, occupation, educational background, sleep time, presence of 
chronic symptoms, household income, economic situation, and physical condition (the questionnaire on the physical condition of mothers of severely disabled children [14] was used). Higher scores indicated poorer physical condition. Cronbach's alpha in this study was 0.94 , and life event items (10 yes-or-no questions) were created with reference to Natsume et al.'s life events scale [15].

\subsubsection{Awareness of Social Support}

The revised version of the Social Support Scale of Home Caregivers [16] was used. The scale is composed of 8 items on emotional support, 2 items on practical support, and 3 items on ineffective support (total 13 items). In this study, subjects answered questions regarding the perceived amount of support (how many individuals apply to each item) with "present" or "absent”. Subjects were asked to answer with "within the family" or "outside of the family" to each item regarding the source of support (multiple answers were allowed from 11 options in the original version). In this study, the 3 ineffective support items and 10 other items were each treated as separate variables for negative and positive support during analysis. Cronbach's alpha in this study was 0.80 for "positive social support from within the family," 0.76 for "negative social support from within the family," 0.84 for "positive social support from outside of the family," and 0.56 for "negative social support from outside of the family" (hereafter, positive social support is treated as social support as long as there is no alternate notation).

\subsubsection{Evaluation of Child Rearing}

i) Positive feelings towards child rearing (positive evaluation)

The positive evaluation subscales of the Cognitive Caregiving Appraisal [17] were used. The scale is composed of 6 items for caregiving satisfaction, 4 items for positive feelings towards the care recipient, and 3 items for sense of self-growth (total 13 items) and is rated with a 4-point scale. A higher score indicates stronger positive feelings towards child rearing. Cronbach's alpha was 0.80, 0.82 and 0.75 , respectively, for each of the above-mentioned subscales. Some of the notations were modified considering the care recipients in this study were children. Of the 4 items for positive feelings towards the care recipient, the caregivers of severely disabled children had marked difficulty regarding the following 3 items: determining whether "(the child was) thankful," "(the child) and the caregiver understood each other's feelings" and "(the child) thought positively of the caregiver;” therefore, these items were excluded from the analysis. Cronbach’s alpha of the 10 items was 0.82.

ii) Negative feelings towards child rearing (negative evaluation)

The short, Japanese version of the Zarit Caregiver Burden Interview [18] was used. The scale is composed of a total of 8 items rated with a 5-point scale and divided into 2 factors: 5 personal burden items and 3 role burden items. Cronbach's alpha for all 8 items is 0.89 and Cronbach's alpha in this study was 0.83 .

\subsection{Analysis}

The descriptive statistics (name, frequency and ratio for the ordinal scale, and mean and standard deviation for the interval scale) of each obtained variable were calculated.

The association of empowerment (family, service system, and community/political domains) and positive feelings towards child rearing with other variables (explanatory variables) was examined. The $t$-test or Spearman's rank correlation coefficient were used to examine the association with bivariates.

A multiple regression analysis was conducted with the three empowerment domains as objective variables. Variables (excluding positive feelings towards child rearing) that were found to be associated with empowerment in a univariate analysis were introduced as explanatory variables. Of the explanatory variables, variables for child and family attributes were introduced first, followed by variables for social support.

We conducted a multiple regression analysis with positive feelings towards child rearing as the objective variable. Variables for which an association with positive feelings towards child rearing and each empowerment domain was seen in a univariate analysis were introduced as explanatory variables.

IBM SPSS 21 statistical software was used for the analyses. The significance level was set at 5\% on both sides. However, the significance level was set at $10 \%$ in the multiple regression analysis to enable a more exploratory interpretation of the results.

\subsection{Ethical Considerations}

The subjects were asked to cooperate after being given verbal and written explanations of the purpose of the 
study. Simple, easily understood expressions were used to explain the study purpose. Cooperation was voluntary for the subjects and returning the anonymous self-administered questionnaire was considered to indicate consent.

The ethics committees of the Faculty of Medicine, the University of Tokyo, University of Tsukuba Hospital, Ibaraki Disabled Children's Hospital, and National Rehabilitation Center for Children with Disabilities approved this study.

\section{Results}

A total of 122 questionnaires were distributed and 76 were returned (recovery rate 62.3\%). Of these, one questionnaire was excluded due to noticeable deficits in each empowerment domain ( 5 of the 12 items in the family domain, 5 of the 12 items in the service system domain and 6 of the 10 items in the community/political domain). Responses from a total of 75 individuals were consequently included in the final analysis (valid response rate $61.5 \%)$.

\subsection{Child, Subject and Family Attributes}

The children of 66 of the 75 (88.0\%) subjects had experienced disability onset at less than 1 year of age. The main diagnoses were cerebral palsy, sequelae of hypoxic encephalopathy in the perinatal period, chromosomal abnormalities, and congenital neurological disease. Those who had experienced disability onset at 1 year of age or older had diseases such as bacterial meningitis and post-measles encephalitis. Twenty-eight (37.3\%) were profoundly severely disabled children or quasi-profoundly severely disabled children according to the score for severely disabled children. All children were visiting the facility on an outpatient basis and most visited at a frequency of once per month (60 subjects, 80\%). The mean time required to visit outpatient facilities was 50.3 minutes. Table 1 shows the child attributes. Table 2 shows the subject and family attributes.

The score for empowerment was $37.02 \pm 7.47$ for the family domain, $39.09 \pm 7.40$ for the service system domain and $25.06 \pm 6.18$ for the community/political domain (mean \pm standard deviation).

\subsection{Association between Empowerment and Other Variables}

\subsubsection{Univariate Analysis}

Subjects visiting facilities in Tokyo had higher empowerment scores for the family and service system domains than those visiting other facilities. The empowerment score for the service system domain was lower if the child had problematic behavior or habits and some kind of sleep problem. Moreover, subjects who had experienced life events and subjects who used at-home services had a higher level of empowerment. The level of empowerment also increased the more satisfied subjects were with their livelihood and the more aware they were of social support from within and outside of the family. These data are shown in Table 3 and Table 4.

On examining the association between empowerment and each life event, the level of empowerment also tended to be higher in cases where there was "death of someone in the family" or "serious illness or accident of someone in the family". These data are shown in Table 5.

\subsubsection{Multiple Regression Analysis}

Variables (facilities, sleep problems, life events, livelihood) for which an association was seen in the univariate analysis were introduced as explanatory variables. Only 10 subjects responded with "present" to "problematic behavior and habits in the child". However, considering the mental and physical function of severely disabled children, it is unlikely that the children were deliberately exhibiting problematic behavior. This item was therefore not added to the explanatory variables.

Variables for child and family attributes were introduced first, followed by variables for social support. The results are shown in Table 6.

1) Facilities, sleep problems of the child, life events and livelihood

The model containing only the above 4 variables (model 1), excluding "facilities" in the community/political domain, contributed significantly to empowerment. Thereafter, on introducing variables for social support (model 2), the standard partial regression coefficient $(\beta)$ of "facilities" was reduced and the contribution to empowerment was no longer seen. 
Table 1. Child attributes.

\begin{tabular}{|c|c|c|c|c|c|}
\hline & & $\mathrm{N}$ & $\%$ & Mean \pm SD & [range] \\
\hline \multirow[t]{2}{*}{ Facility } & Outside of Tokyo & 40 & 53.3 & & \\
\hline & Tokyo & 35 & 46.7 & & \\
\hline \multirow[t]{3}{*}{$\begin{array}{l}\text { Time required to go to facility } \\
\text { from residence (minutes) }\end{array}$} & Outside of Tokyo & 40 & & $48.50 \pm 30.74$ & {$[5-180]$} \\
\hline & Tokyo & 35 & & $52.43 \pm 35.68$ & [10 - 210] \\
\hline & Total & 75 & & $50.33 \pm 33.20$ & {$[5-210]$} \\
\hline \multirow[t]{2}{*}{ Sex of the child } & Male & 47 & 62.7 & & \\
\hline & Female & 28 & 37.3 & & \\
\hline Age of the child (years) & & 75 & & $11.95 \pm 3.97$ & {$[5-18]$} \\
\hline \multirow[t]{3}{*}{ Age of disability onset } & $<1$ year of age & 64 & 85.3 & & \\
\hline & $\geq 1$ year of age & 9 & 12 & & \\
\hline & No answer & 2 & 2.7 & & \\
\hline \multirow[t]{2}{*}{ Physical disability certificate } & Grade 1 & 69 & 92 & & \\
\hline & Grade 2 & 6 & 8 & & \\
\hline \multirow[t]{4}{*}{ Rehabilitation handbook } & Most severe & 35 & 46.7 & & \\
\hline & Severe & 3 & 4 & & \\
\hline & Do not have one & 33 & 44 & & \\
\hline & No answer & 4 & 5.3 & & \\
\hline \multirow[t]{3}{*}{ Respiratory problems } & Present & 35 & 46.7 & & \\
\hline & Absent & 33 & 44 & & \\
\hline & No answer & 7 & 9.3 & & \\
\hline \multirow[t]{2}{*}{ Child disability classification } & Severely disabled child & 28 & 37.3 & & \\
\hline & Other & 47 & 62.7 & & \\
\hline \multirow[t]{3}{*}{ Gastroesophageal reflux } & Present & 20 & 26.7 & & \\
\hline & Absent & 52 & 69.3 & & \\
\hline & No answer & 3 & 4 & & \\
\hline \multirow[t]{3}{*}{ Problematic behavior and habits } & Present & 11 & 14.7 & & \\
\hline & Absent & 63 & 84 & & \\
\hline & No answer & 1 & 1.3 & & \\
\hline \multirow[t]{3}{*}{ Seizures more than once a week } & Present & 36 & 48 & & \\
\hline & Absent & 38 & 50.7 & & \\
\hline & No answer & 1 & 1.3 & & \\
\hline \multirow[t]{2}{*}{ Use of anticonvulsants } & Present & 63 & 84 & & \\
\hline & Absent & 12 & 16 & & \\
\hline \multirow[t]{3}{*}{ Sites of contracture } & Present & 59 & 78.7 & & \\
\hline & Absent & 15 & 20 & & \\
\hline & No answer & 1 & 1.3 & & \\
\hline \multirow[t]{3}{*}{ Sleep problems } & Present & 40 & 53.3 & & \\
\hline & Absent & 34 & 45.3 & & \\
\hline & No answer & 1 & 1.3 & & \\
\hline \multirow[t]{2}{*}{ Use of sleep-inducing drugs } & Present & 22 & 29.3 & & \\
\hline & Absent & 53 & 70.7 & & \\
\hline
\end{tabular}


Table 2. Subject and family attributes.

\begin{tabular}{|c|c|c|c|c|c|}
\hline & & $\mathrm{N}$ & $\%$ & Mean \pm SD & [range] \\
\hline \multirow[t]{2}{*}{ Relationship to the child } & Mother & 74 & 98.7 & & \\
\hline & Father & 1 & 1.3 & & \\
\hline Age of subject (years) & & 75 & & $42.39 \pm 5.85$ & {$[29-56]$} \\
\hline \multirow[t]{2}{*}{ Marital status } & Married & 66 & 88 & & \\
\hline & Divorced & 9 & 12 & & \\
\hline \multirow[t]{2}{*}{ Employment status } & Employed & 13 & 17.3 & & \\
\hline & Unemployed & 62 & 82.7 & & \\
\hline \multirow[t]{4}{*}{ Highest level of education } & Middle school & 1 & 1.3 & & \\
\hline & High school & 28 & 37.3 & & \\
\hline & Junior college/vocational school & 33 & 44 & & \\
\hline & University or higher & 13 & 17.3 & & \\
\hline Sleep time (hours) & & 73 & & $5.48 \pm 0.84$ & [3 - 7] \\
\hline \multirow[t]{2}{*}{ Chronic symptoms } & Present & 31 & 41.3 & & \\
\hline & Absent & 44 & 58.7 & & \\
\hline \multirow[t]{2}{*}{ Family occupation } & Self-employed & 10 & 13.3 & & \\
\hline & Other & 65 & 86.7 & & \\
\hline Number of cohabiting family members & & 75 & & $4.01 \pm 0.97$ & {$[2-6]$} \\
\hline \multirow[t]{2}{*}{ Living arrangements with grandparents } & Living together & 9 & 12 & & \\
\hline & Living apart & 66 & 88 & & \\
\hline \multirow[t]{4}{*}{ Number of siblings of the child } & 0 & 24 & 32 & & \\
\hline & 1 & 33 & 44 & & \\
\hline & 2 & 15 & 20 & & \\
\hline & 3 & 3 & 4 & & \\
\hline \multirow[t]{2}{*}{ Life events } & Present & 33 & 44 & & \\
\hline & Absent & 42 & 56 & & \\
\hline \multirow[t]{6}{*}{ Annual household income (million yen) } & $<3$ & 11 & 14.7 & & \\
\hline & 3 to 5 & 18 & 24 & & \\
\hline & 5 to 7 & 31 & 41.3 & & \\
\hline & 7 to 10 & 6 & 8 & & \\
\hline & $\geq 10$ & 11 & 14.7 & & \\
\hline & No answer & 3 & 4 & & \\
\hline \multirow[t]{4}{*}{ Livelihood } & Dissatisfied & 11 & 14.7 & & \\
\hline & Slightly dissatisfied & 18 & 24 & & \\
\hline & Slightly satisfied & 31 & 41.3 & & \\
\hline & Satisfied & 13 & 17.3 & & \\
\hline
\end{tabular}




\section{Continued}

\begin{tabular}{|c|c|c|c|c|c|}
\hline & No answer & 2 & 2.7 & & \\
\hline Physical condition score & & 75 & & $77.03 \pm 18.44$ & [43 - 120] \\
\hline \multirow[t]{2}{*}{ Use of at-home services } & Present & 25 & 33.3 & & \\
\hline & Absent & 50 & 66.7 & & \\
\hline \multirow[t]{2}{*}{ Informal support } & Yes & 61 & 81.3 & & \\
\hline & No & 14 & 18.7 & & \\
\hline \multicolumn{2}{|c|}{ Social support (positive, family) } & 75 & & $7.31 \pm 2.44$ & {$[0-10]$} \\
\hline \multicolumn{2}{|c|}{ Social support (negative, family) } & 75 & & $0.40 \pm 0.84$ & {$[0-3]$} \\
\hline \multicolumn{2}{|c|}{ Social support (positive, outside of the family) } & 75 & & $6.55 \pm 2.63$ & {$[0-10]$} \\
\hline \multicolumn{2}{|c|}{ Social support (negative, outside of the family) } & 75 & & $0.16 \pm 0.49$ & {$[0-3]$} \\
\hline \multicolumn{2}{|c|}{ Negative feelings towards child rearing } & 75 & & $16.39 \pm 5.71$ & {$[8-35]$} \\
\hline \multicolumn{2}{|c|}{ Positive feelings towards child rearing } & 74 & & $33.60 \pm 4.12$ & {$[24-40]$} \\
\hline \multicolumn{2}{|c|}{ Empowerment (family) } & 74 & & $37.02 \pm 7.47$ & [15 - 53] \\
\hline \multicolumn{2}{|c|}{ Empowerment (services system) } & 73 & & $39.09 \pm 7.40$ & {$[17-60]$} \\
\hline \multicolumn{2}{|c|}{ Empowerment (community/political) } & 75 & & $25.06 \pm 6.18$ & [12 - 40] \\
\hline
\end{tabular}

Table 3. Association of empowerment and positive feelings towards child rearing and explanatory variables.

\begin{tabular}{|c|c|c|c|c|c|c|c|c|c|c|c|c|c|c|c|c|c|}
\hline & & \multicolumn{4}{|c|}{$\begin{array}{l}\text { Empowerment } \\
\text { (family) }\end{array}$} & \multicolumn{4}{|c|}{$\begin{array}{l}\text { Empowerment } \\
\text { (service system) }\end{array}$} & \multicolumn{4}{|c|}{$\begin{array}{c}\text { Empowerment } \\
\text { (community/political) }\end{array}$} & \multicolumn{4}{|c|}{$\begin{array}{l}\text { Positive feelings } \\
\text { towards child rearing }\end{array}$} \\
\hline & & $\mathrm{N}$ & Mean & $\mathrm{SD}$ & $\mathrm{p}$ & $\mathrm{N}$ & Mean & $\mathrm{SD}$ & $\mathrm{p}$ & $\mathrm{N}$ & Mean & SD & $\mathrm{p}$ & $\mathrm{N}$ & Mean & $\mathrm{SD}$ & $\mathrm{p}$ \\
\hline \multirow{2}{*}{ Facility } & Outside of Tokyo & 39 & 34.85 & 7.34 & $* *$ & 39 & 37.20 & 6.80 & $*$ & 40 & 24.16 & 6.13 & & 39 & 32.69 & 3.98 & * \\
\hline & Tokyo & 35 & 39.44 & 6.94 & & 34 & 41.26 & 7.55 & & 35 & 26.09 & 6.16 & & 35 & 34.62 & 4.09 & \\
\hline \multirow{2}{*}{$\begin{array}{c}\text { Age of } \\
\text { disability onset }\end{array}$} & $>1$ year of age & 63 & 36.82 & 7.49 & & 62 & 38.87 & 7.03 & & 64 & 24.84 & 5.81 & & 63 & 33.37 & 3.82 & \\
\hline & $\geq 1$ year of age & 9 & 37.11 & 7.62 & & 9 & 39.62 & 9.81 & & 9 & 25.89 & 7.06 & & 9 & 35.83 & 4.69 & \\
\hline \multirow{2}{*}{$\begin{array}{l}\text { Physical } \\
\text { disability } \\
\text { certificate }\end{array}$} & Grade 1 & 68 & 37.11 & 7.45 & & 67 & 38.93 & 7.33 & & 69 & 24.96 & 6.25 & & 68 & 33.72 & 4.05 & \\
\hline & Grade 2 & 6 & 36.00 & 8.34 & & 6 & 40.92 & 8.63 & & 6 & 26.17 & 5.64 & & 6 & 32.31 & 5.06 & \\
\hline \multirow{2}{*}{$\begin{array}{l}\text { Rehabilitation } \\
\text { handbook }\end{array}$} & Present & 37 & 35.40 & 8.11 & & 36 & 38.00 & 6.93 & & 38 & 24.91 & 6.64 & & 38 & 32.61 & 4.04 & * \\
\hline & Absent & 33 & 38.67 & 6.69 & & 33 & 40.08 & 8.04 & & 33 & 25.64 & 5.87 & & 33 & 34.68 & 4.07 & \\
\hline \multirow{2}{*}{$\begin{array}{l}\text { Respiratory } \\
\text { problems }\end{array}$} & Present & 35 & 36.85 & 7.35 & & 35 & 39.04 & 6.35 & & 35 & 24.76 & 5.78 & & 34 & 34.38 & 4.26 & \\
\hline & Absent & 32 & 37.53 & 8.15 & & 32 & 40.10 & 8.45 & & 33 & 25.79 & 6.58 & & 33 & 32.51 & 3.92 & \\
\hline \multirow{2}{*}{$\begin{array}{l}\text { Child disability } \\
\text { classification }\end{array}$} & $\begin{array}{l}\text { Severely disabled } \\
\text { child }\end{array}$ & 28 & 37.09 & 7.43 & & 27 & 39.54 & 8.08 & & 28 & 24.98 & 6.25 & & 27 & 34.18 & 4.19 & \\
\hline & Other & 46 & 36.98 & 7.57 & & 46 & 38.83 & 7.04 & & 47 & 25.11 & 6.20 & & 47 & 33.27 & 4.09 & \\
\hline \multirow{2}{*}{$\begin{array}{l}\text { Gastroesophageal } \\
\text { reflux }\end{array}$} & Present & 20 & 38.66 & 6.32 & & 19 & 41.11 & 6.31 & & 20 & 25.50 & 4.36 & & 19 & 34.21 & 4.48 & \\
\hline & Absent & 52 & 36.60 & 7.86 & & 51 & 38.74 & 7.68 & & 52 & 25.22 & 6.77 & & 52 & 33.15 & 3.99 & \\
\hline \multirow{2}{*}{$\begin{array}{c}\text { Problematic } \\
\text { behavior } \\
\text { and habits }\end{array}$} & Present & 10 & 33.12 & 5.88 & & 10 & 35.91 & 3.00 & $* *$ & 11 & 22.36 & 5.20 & & 11 & 30.83 & 3.71 & ** \\
\hline & Absent & 63 & 37.83 & 7.43 & & 62 & 39.80 & 7.66 & & 63 & 25.64 & 6.22 & & 62 & 34.22 & 3.92 & \\
\hline \multirow{2}{*}{$\begin{array}{l}\text { Seizures more } \\
\text { than once a week }\end{array}$} & Present & 36 & 38.07 & 6.94 & & 36 & 40.06 & 6.59 & & 36 & 25.03 & 5.47 & & 35 & 33.87 & 4.29 & \\
\hline & Absent & 37 & 35.92 & 7.98 & & 37 & 38.15 & 8.09 & & 38 & 25.09 & 6.93 & & 38 & 33.26 & 4.01 & \\
\hline
\end{tabular}




\begin{tabular}{|c|c|c|c|c|c|c|c|c|c|c|c|c|c|c|c|c|c|}
\hline \multirow{2}{*}{$\begin{array}{c}\text { Use of } \\
\text { anticonvulsants }\end{array}$} & Present & 63 & 36.99 & 7.86 & & 62 & 39.00 & 7.72 & & 63 & 25.01 & 6.42 & & 62 & 33.67 & 4.16 & \\
\hline & Absent & 11 & 37.18 & 4.90 & & 11 & 39.60 & 5.51 & & 12 & 25.33 & 4.91 & & 12 & 33.24 & 4.06 & \\
\hline \multirow{2}{*}{$\begin{array}{c}\text { Sites of } \\
\text { contracture }\end{array}$} & Present & 59 & 37.77 & 6.83 & & 58 & 39.82 & 7.13 & & 59 & 25.60 & 5.95 & & 58 & 33.96 & 4.24 & \\
\hline & Absent & 15 & 34.07 & 9.28 & & 14 & 36.21 & 8.28 & & 15 & 23.27 & 6.97 & & 15 & 32.01 & 3.36 & \\
\hline \multirow{2}{*}{ Sleep problems } & Present & 39 & 35.54 & 6.83 & & 39 & 37.46 & 6.62 & * & 40 & 23.81 & 5.65 & & 40 & 33.17 & 4.04 & \\
\hline & Absent & 34 & 38.75 & 7.99 & & 33 & 40.96 & 8.01 & & 34 & 26.62 & 6.56 & & 34 & 34.11 & 4.22 & \\
\hline \multirow{2}{*}{$\begin{array}{c}\text { Use of } \\
\text { sleep-inducing } \\
\text { drugs }\end{array}$} & Present & 22 & 35.00 & 7.20 & & 21 & 38.48 & 7.78 & & 22 & 23.34 & 5.30 & & 21 & 33.48 & 3.79 & \\
\hline & Absent & 52 & 37.88 & 7.48 & & 52 & 39.34 & 7.30 & & 53 & 25.77 & 6.41 & & 53 & 33.65 & 4.28 & \\
\hline \multirow{2}{*}{ Marital status } & Married & 66 & 37.18 & 7.30 & & 64 & 39.15 & 7.20 & & 66 & 25.44 & 6.23 & & 65 & 33.49 & 4.21 & \\
\hline & Divorced & 8 & 35.75 & 9.22 & & 9 & 38.68 & 9.14 & & 9 & 22.27 & 5.23 & & 9 & 34.44 & 3.54 & \\
\hline \multirow{2}{*}{$\begin{array}{l}\text { Employment } \\
\text { status }\end{array}$} & Employed & 13 & 35.55 & 5.69 & & 13 & 37.08 & 5.31 & & 13 & 24.31 & 5.42 & & 13 & 33.77 & 4.80 & \\
\hline & Unemployed & 61 & 37.34 & 7.80 & & 60 & 39.53 & 7.74 & & 62 & 25.22 & 6.35 & & 61 & 33.57 & 4.01 & \\
\hline \multirow{2}{*}{$\begin{array}{l}\text { Chronic } \\
\text { symptoms }\end{array}$} & Present & 30 & 38.49 & 6.90 & & 31 & 40.74 & 6.23 & & 31 & 26.01 & 6.97 & & 31 & 34.76 & 4.00 & * \\
\hline & Absent & 44 & 36.02 & 7.75 & & 42 & 37.87 & 8.01 & & 44 & 24.39 & 5.53 & & 43 & 32.77 & 4.05 & \\
\hline \multirow{2}{*}{$\begin{array}{c}\text { Family } \\
\text { occupation }\end{array}$} & Self-employed & 10 & 38.95 & 7.87 & & 10 & 40.00 & 7.87 & & 10 & 25.20 & 6.39 & & 10 & 35.36 & 4.11 & \\
\hline & Other & 64 & 36.72 & 7.42 & & 63 & 38.95 & 7.37 & & 65 & 25.04 & 6.19 & & 64 & 33.33 & 4.09 & \\
\hline \multirow{2}{*}{$\begin{array}{c}\text { Living } \\
\text { arrangements } \\
\text { with } \\
\text { grandparents }\end{array}$} & Living together & 8 & 34.38 & 4.37 & & 9 & 36.57 & 5.48 & & 9 & 22.22 & 3.93 & & 8 & 32.75 & 3.62 & \\
\hline & Living apart & 66 & 37.34 & 7.72 & & 64 & 39.45 & 7.59 & & 66 & 25.45 & 6.34 & & 66 & 33.71 & 4.19 & \\
\hline \multirow{2}{*}{ Life events } & Present & 32 & 39.50 & 5.53 & ** & 33 & 41.00 & 6.21 & * & 33 & 26.76 & 6.19 & * & 32 & 33.99 & 3.50 & \\
\hline & Absent & 42 & 35.13 & 8.23 & & 40 & 37.51 & 7.98 & & 42 & 23.72 & 5.90 & & 42 & 33.31 & 4.56 & \\
\hline \multirow{2}{*}{$\begin{array}{l}\text { Use of at-home } \\
\text { services }\end{array}$} & Present & 24 & 40.06 & 6.77 & * & 24 & 42.30 & 7.52 & $* *$ & 25 & 27.04 & 6.39 & * & 25 & 35.56 & 2.55 & $* *$ \\
\hline & Absent & 50 & 35.56 & 7.41 & & 49 & 37.52 & 6.88 & & 50 & 24.07 & 5.88 & & 49 & 32.60 & 4.42 & \\
\hline \multirow{2}{*}{$\begin{array}{c}\text { Informal } \\
\text { support }\end{array}$} & Present & 14 & 38.64 & 4.97 & & 13 & 40.38 & 5.20 & & 14 & 27.79 & 5.21 & & 14 & 34.72 & 3.66 & \\
\hline & Absent & 60 & 36.64 & 7.92 & & 60 & 38.81 & 7.80 & & 61 & 24.43 & 6.25 & & 60 & 33.34 & 4.21 & \\
\hline
\end{tabular}

Unpaired $t$-test ${ }^{*} \mathrm{p}<0.05,{ }^{* *} \mathrm{p}<0.01$.

2) Awareness of social support and usage of at-home services

Awareness of social support from within the family was not found to contribute to empowerment. On the other hand, awareness of social support from outside of the family was the variable that contributed the most to empowerment. In particular, the standard partial regression coefficient $(\beta)$ increased further in the service system and community/political domains compared with the family domain. Use of at-home services was found to contribute to empowerment in the service system domain.

The increase in the rate of contribution from model 1 to model 2 greatly indicated that awareness of social support from outside of the family had a strong influence in each of the family, service system, and community/ political domains.

\subsection{Association between Positive Feelings towards Child Rearing and Other Variables}

\subsubsection{Univariate Analysis}

Subjects visiting facilities in Tokyo had stronger positive feelings towards child rearing. These feelings were strong in subjects without a rehabilitation handbook and whose child exhibited no problematic behavior or habits. Subjects themselves with chronic symptoms and few cohabitating family members or siblings had stronger 
Table 4. Correlation of empowerment and positive feelings towards child rearing and explanatory variables.

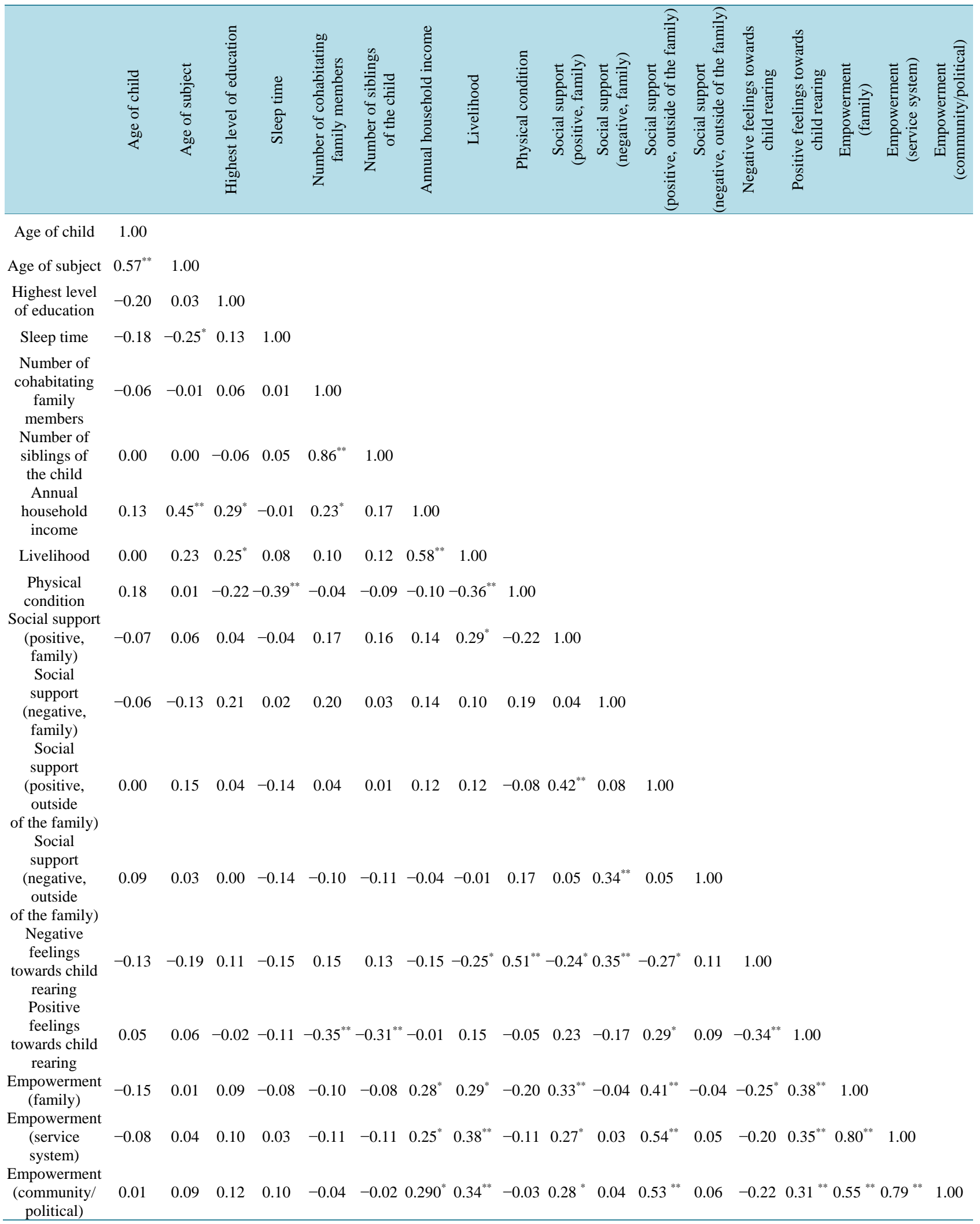

Spearman's rank correlation coefficient. ${ }^{*} \mathrm{p}<0.05,{ }^{* *} \mathrm{p}<0.01$. 
Table 5. Association between empowerment and each life event.

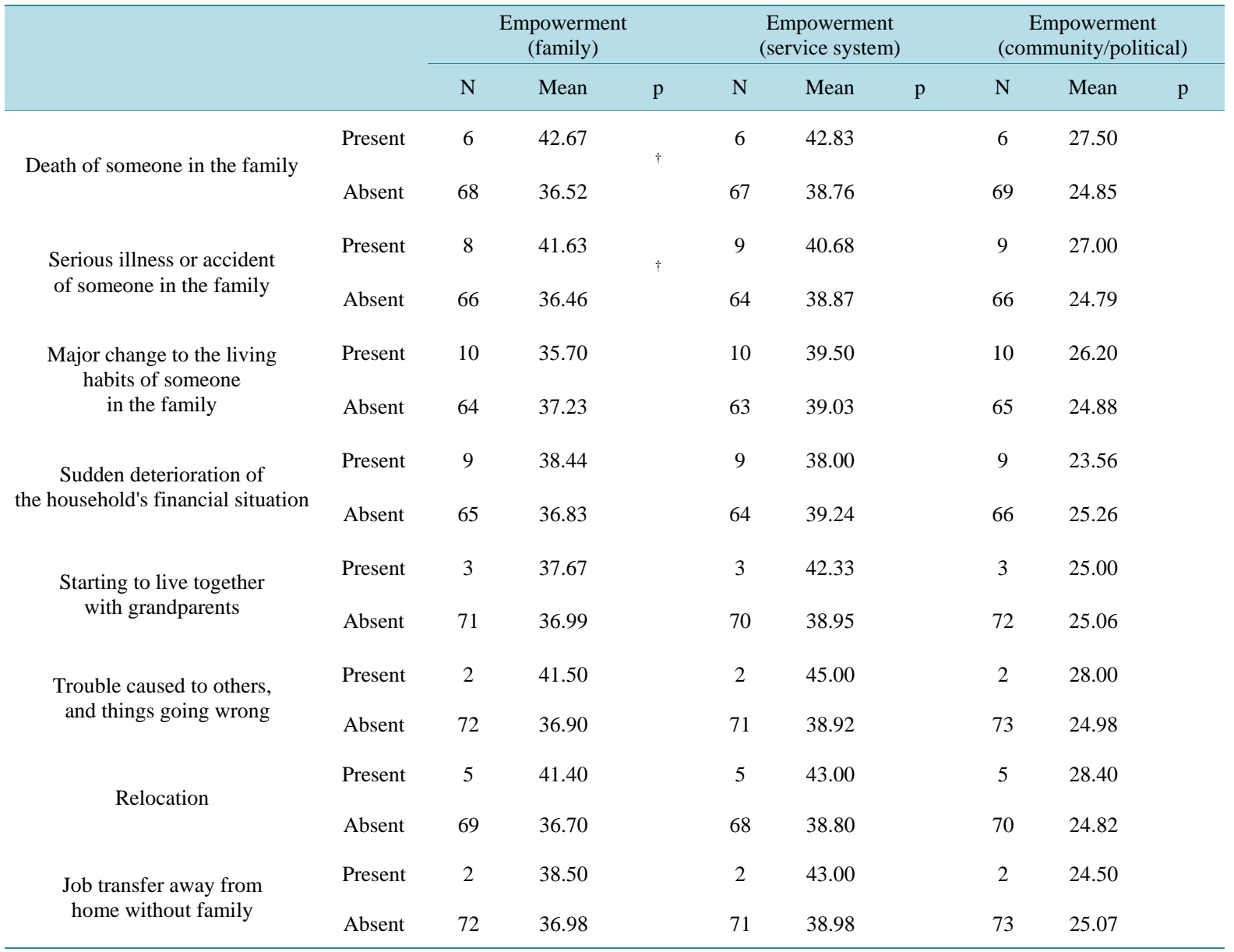

Unpaired $t$-test. ${ }^{\dagger} \mathrm{p}<0.10$. No subjects responded present to “Job transfer or change of schools” or "Birth of a child”.

Table 6. Results of the multiple regression analysis with empowerment.

\begin{tabular}{|c|c|c|c|c|c|c|c|c|c|c|c|c|}
\hline & \multicolumn{4}{|c|}{$\begin{array}{l}\text { Empowerment } \\
\text { (family) }\end{array}$} & \multicolumn{4}{|c|}{$\begin{array}{l}\text { Empowerment } \\
\text { (service system) }\end{array}$} & \multicolumn{4}{|c|}{$\begin{array}{c}\text { Empowerment } \\
\text { (community/political) }\end{array}$} \\
\hline & \multicolumn{2}{|c|}{ Model 1} & \multicolumn{2}{|c|}{ Model 2} & \multicolumn{2}{|c|}{ Model 1} & \multicolumn{2}{|c|}{ Model 2} & \multicolumn{2}{|c|}{ Model 1} & \multicolumn{2}{|c|}{ Model 2} \\
\hline & $\beta$ & $\mathrm{p}$ & $\beta$ & $\mathrm{p}$ & $\beta$ & $\mathrm{p}$ & $\beta$ & $\mathrm{p}$ & $\beta$ & $\mathrm{p}$ & $\beta$ & $\mathrm{p}$ \\
\hline $\begin{array}{c}\text { Facility } \\
\text { (outside of Tokyo 1, Tokyo 0) }\end{array}$ & -0.27 & * & -0.12 & & -0.23 & $*$ & -0.06 & & -0.09 & & -0.12 & \\
\hline Sleep problems (present 1 , absent 0 ) & -0.33 & $* *$ & -0.25 & * & -0.29 & ** & -0.21 & * & -0.28 & * & -0.25 & $*$ \\
\hline Life events (present 1 , absent 0 ) & 0.32 & $* *$ & 0.26 & $* *$ & 0.28 & $*$ & 0.21 & $*$ & 0.30 & ** & 0.26 & $* *$ \\
\hline Livelihood & 0.22 & * & 0.19 & + & 0.28 & * & 0.26 & * & 0.28 & * & 0.19 & + \\
\hline $\begin{array}{l}\text { Awareness of social support } \\
\text { (within the family) }\end{array}$ & & & 0.00 & & & & -0.13 & & & & 0.00 & \\
\hline $\begin{array}{l}\text { Awareness of social support } \\
\text { (outside of the family) }\end{array}$ & & & 0.33 & $* *$ & & & 0.45 & $* * *$ & & & 0.33 & ** \\
\hline $\begin{array}{l}\text { Use of at-home services } \\
\text { (present 1, absent } 0 \text { ) }\end{array}$ & & & 0.16 & & & & 0.19 & + & & & 0.16 & \\
\hline Adjusted R-squared & 0.29 & *** & 0.38 & *** & 0.26 & *** & 0.44 & ${ }^{* * *}$ & 0.21 & ** & 0.39 & ${ }^{* * *}$ \\
\hline Amount of R-squared change & & & 0.11 & $* *$ & & & 0.19 & $* * *$ & & & 0.20 & $* * *$ \\
\hline
\end{tabular}

${ }^{\dagger} \mathrm{p}<0.1,{ }^{*} \mathrm{p}<0.05,{ }^{* *} \mathrm{p}<0.01{ }^{* * *} \mathrm{p}<0.001 . \beta$ : Standard partial regression coefficient. 
positive feelings towards child rearing. Moreover, these feelings were stronger in those who were aware of social support from outside of the family and who used at-home services. Positive feelings towards child rearing were stronger if negative feelings towards child rearing were weak and empowerment (each domain) was high. These data are shown in Table 3 and Table 4.

\subsubsection{Multiple Regression Analysis}

Of the variables for which an association with positive feelings towards child rearing was seen in the univariate analysis, empowerment and variables for negative feelings towards child rearing and social support were selected as explanatory variables. In this study, social support and empowerment were assumed to be variables directly associated with positive feelings towards child rearing. However, among the variables for other attributes, negative feelings towards child rearing in particular had thus far been treated as a contrast to positive feelings towards child rearing; thus, the control of negative feelings is an important factor when examining support to promote positive feelings towards child rearing.

As a result, social support from outside of the family was not found to contribute to positive feelings towards child rearing. On the other hand, use of at-home services was found to contribute. The most contribution was seen from negative feelings towards child rearing. It was revealed that positive feelings towards child rearing were enhanced when negative feelings towards child rearing were reduced. Contributions were seen in the family and community/political domains of empowerment. These data are shown in Table 7.

\section{Discussion}

\subsection{Subject Attributes}

In this study, profoundly severely disabled children and quasi-severely disabled children accounted for $37.3 \%$ of all severely disabled children. The number of profoundly severely disabled children and quasi-severely disabled children is estimated at 10,000 nationwide in Japan, and at least 6,000 of these children live at home [19]. Given that the number of severely disabled children living at home is estimated to be 28,000 [1], it is likely that profoundly severely disabled children and quasi-severely disabled children account for at least about $20 \%$ of these severely disabled children living at home. There may therefore have been a strong bias towards subjects with profoundly severely disabled children and quasi-severely disabled children in this study. This is thought to have been influenced by the fact that subjects were limited to those who made regular outpatient visits, since the subjects in this study were recruited during outpatient visits.

The mean score for "physical condition," which indicates the mental and physical state of the subjects in this study, was 77 points. This score is almost the same as that in a similar previous study of mothers of severely disabled children living at home [14]. The mean sleep time in previous studies [14] [20] was stated to be consistently 5 to 6 hours, which was the same as in this study. The sleep time of caregivers of severely disabled children is short when compared to the mean daily sleep time of 6 to 7 hours for adult women [21].

Table 7. Results of multiple regression analysis with positive feelings towards child rearing.

\begin{tabular}{|c|c|c|c|c|c|c|}
\hline & $\beta$ & $\mathrm{p}$ & $\beta$ & $\mathrm{p}$ & $\beta$ & $\mathrm{p}$ \\
\hline $\begin{array}{l}\text { Negative feelings } \\
\text { towards child rearing }\end{array}$ & -0.27 & * & -0.29 & $* *$ & -0.29 & ** \\
\hline $\begin{array}{l}\text { Awareness of social support } \\
\text { (outside of the family) }\end{array}$ & 0.13 & & 0.11 & & 0.11 & \\
\hline $\begin{array}{l}\text { Use of at-home services } \\
\text { (present } 1 \text {, absent } 0 \text { ) }\end{array}$ & 0.25 & * & 0.26 & $*$ & 0.28 & $* *$ \\
\hline Empowerment (family) & 0.22 & $\dagger$ & & & & \\
\hline $\begin{array}{l}\text { Empowerment } \\
\text { (service system) }\end{array}$ & & & 0.18 & & & \\
\hline $\begin{array}{c}\text { Empowerment } \\
\text { (community/political) }\end{array}$ & & & & & 0.20 & $\dagger$ \\
\hline Adjusted R-squared & 0.27 & $* * *$ & 0.25 & $* * *$ & 0.38 & *** \\
\hline
\end{tabular}


In a study that examined the families of children with developmental disabilities in Japan [11], the empowerment score was $34.4 \pm 9.0$ for the family domain, $36.1 \pm 9.2$ for the service system domain and $21.2 \pm 6.5$ for the community/political domain (mean \pm standard deviation). Meanwhile, the empowerment score in this study, which examined the families of severely disabled children, was $37.02 \pm 7.47$ for the family domain, $39.09 \pm$ 7.40 for the service system domain and $25.06 \pm 6.18$ for the community/political domain (mean \pm standard deviation). The score for each domain was significantly higher in this study, which examined the families of severely disabled children (family domain: $\mathrm{p}<0.05$, service system domain: $\mathrm{p}<0.01$, community/political domain: $\mathrm{p}<$ 0.001). Compared with children with developmental disabilities, the need for support of severely disabled children and their families is acknowledged as a long-term requirement and while support remains adequate, it has been provided by support systems and institutions [22]. No studies limited to the families of severely disabled children can be found overseas; the majority of studies examine the families of children with developmental disabilities. In a study by Koren et al., which examined the families of children with emotional and developmental disabilities [9], the mean score for each domain was 45.8 for the family domain, 48.6 for the service system domain and 31.4 for the community/political domain. A study that examined the families of children with developmental disabilities and normal children [23] showed markedly higher scores compared with families in Japan. This was likely due to differences in culture more than the type of disability. Japan has a culture in which modesty is emphasized, in which one step is taken back to value overall harmony, as opposed to the individual asserting oneself. This makes a simple comparison of Japanese and overseas scores for empowerment difficult. Further accumulation of empirical studies on empowerment will therefore be needed in Japan in the future.

\subsection{Factors Related to Empowerment and Support Strategies}

A hierarchical multiple regression analysis in this study revealed that three variables contributed to empowerment: sleep problems of the child, life events and livelihood. Facilities did not contribute to empowerment. In terms of variables related to support, awareness of social support from outside of the family contributed to empowerment.

\subsubsection{Facilities, Sleep Problems of the Child, Life Events and Livelihood}

A comparison of facilities in Tokyo with other facilities revealed that facilities in Tokyo scored higher for empowerment in the family and service system domains. A study that examined the families of children with developmental disabilities [11] also found that those visiting facilities in Tokyo scored higher for empowerment. On the other hand, no significant difference was seen in the community/political domain. It is thought that because the items in the community/political domain are regarding government and politics, and because the same laws (e.g. the Services and Supports for Persons with Disabilities Act and Child Welfare Act) apply irrespective of the facilities in this study, inter-facility differences did not have an impact. Furthermore, by introducing other variables in the multiple regression analysis, the differences that arose in the family and service system domain no longer affected empowerment. Thus, the inter-facility difference that emerged in this study can be interpreted as the difference between other variables, particularly awareness of social support from outside of the family and use of at-home services.

Therefore, when providing support to enhance empowerment, focusing on the family's usage of at-home support and awareness of support offered by other services is more effective than lumping facilities or the entire region where the facilities are located together.

The nighttime sleep situation of the child is of particular importance to the family in daily care at home. In addition to respiratory and nutritional management, care for severely disabled children involves control of seizures, muscle tone and other factors. This care essentially needs to be provided day and night. In such situations, the child obviously needs to rest at night, but the family providing the care also needs to rest at night. If anything hinders the child's nighttime sleep, the family providing care cannot rest and this has an impact on daytime activities [24]. In this study, the mean sleep time of subjects was 3 to 6 hours, which is short even when compared to typical adults, and suggests that the subjects were providing childcare with barely any attention to their own physical condition. Nurses must take corrective action by properly asking families about the nighttime situation of the child and taking measures by devising methods of using sleep-inducing drugs and embracing the child through consultations with the family.

The entire family may be deprived of their energy in situations where a family member requires care due to 
illness or an accident. Lifestyle changes such as relocation, job transfers away from home without family and changes in family members can also cause problems with child rearing. However, the results of this study revealed that those who had experienced lifestyle changes (life events) had higher levels of empowerment. A possible interpretation of this is that lifestyle changes acted as a driving force for the family itself to put effort into child rearing. Resilience is a similar concept to empowerment. Resilience is "the psychological trait and ability to adapt and recover from difficult situations despite experiencing previous hardship" [25] and indicates the strength to proactively overcome and thrive against so-called adversity. The process of triggering resilience is complicated and largely unclear, although support from within and outside of the family at least is considered an effective means of triggering such ability [25]. Nonetheless, life events are desirable for child rearing [26]. For example, families may relocate in order to offer an appropriate environment for child rearing, such as a barrier-free environment. Further study will be needed after elucidating how subjects perceive life events.

The multiple regression analysis revealed that sleep problems of the child and livelihood were variables that consistently affected empowerment. The child's sleep rhythm, usage situation of anticonvulsants and the family's financial situation therefore need to be assessed and continuous support needs to be provided based on an understanding of the family's support situation and awareness situation of child rearing.

\subsubsection{Awareness of Social Support and Use of At-Home Services}

The variable that contributed the most as the explanatory variable of empowerment was awareness of social support from outside of the family. Previous studies have suggested an association between empowerment and social support [23] [27], but the situation of receiving support is thought to be similarly important as awareness of the subject themselves and of feeling that they are being supported. In addition to providing practical support, it is important when providing support to understand how the subject perceives their situation and to provide support that works on awareness to alter the subject's perception to a proactive one.

As a source of support, support from both within and outside of the family is necessary for the formation of empowerment [23]. However, support from outside of the family showed a strong association in this study. Specialist knowledge and skills, such as ventilator and enteral nutrition management and coping with seizures, is required for raising a severely disabled child. Total support from professionals for the child, primary caregiver and other family members is therefore particularly important in order for the family to continue raising their child.

To enhance the service level for empowerment, i.e. to improve the ability of a family with a severely disabled child to continue to use services through cooperation with professionals, it is necessary to build a system together with families that allows the continuous use of services.

\subsection{Support Strategies to Enhance Positive Feelings towards Child Rearing}

This study revealed that to enhance positive feelings towards child rearing, negative feelings towards child rearing must first be reduced. Use of at-home services and improving the empowerment of the subject themselves (or family itself) were also found to enhance positive feelings towards child rearing.

Many services offer care, so negative feelings towards child rearing can be reduced by implementing services [3]. However, the fundamental goal of family support is to allow the family, commencing with the primary caregiver, to continue proactively raising their child with a sense of fulfillment. To improve and maintain these positive feelings towards child rearing, it is important during the provision of services to encourage the family to become empowered. For example, services should nurture proactive feelings towards child rearing in the family by focusing on small changes indicative of growth of the child and sharing these with the family. Traditional factors that contribute to positive feelings towards child rearing include social support and negative feelings towards child rearing [3] [23], but this study newly showed that empowerment is a contributing factor. However, the causal relationship between social support and empowerment is said to go both ways [28]. The interaction between variables will need to be examined in the future. Specifically, we propose qualitatively elucidating the process of enhancing positive feelings towards child rearing through social support from the perspective of empowerment and conducting a covariance structure analysis with a larger subject sample.

\subsection{The Limitations and Novelty of This Study}

The subjects of this study were the families of children who regularly visited one of three facilities in the Tokyo 
metropolitan area on an outpatient basis. It is conceivable that some severely disabled children living at home who require little medical care do not make regular visits to facilities. In this study, there may have therefore been a bias towards subjects with severely disabled children with high medical needs. A study with a wider subject sample in other regions and facilities (schools, day care facilities, etc.) will need to be conducted in the future.

The questionnaires used in this study took about 30 minutes to complete and approximately $60 \%$ of the questionnaires were recovered. Some subjects may not have answered their questionnaires due to a lack of time. There is a need for questionnaires that are further refined and a method of explanation that grasps the main points to encourage subjects who did not answer the questionnaire this time to respond in the future.

On the other hand, the findings of this study suggested that support from professionals for the entire family was important because awareness of social support from outside of the family contributed the most to the empowerment of families with severely disabled children with high medical needs. Moreover, this study newly showed that, in addition to the reduction of negative feelings towards child rearing and ensuring social support, empowerment was a factor involved in the improvement and maintenance of positive feelings towards child rearing, which was the fundamental goal of family support. Practical family support for the purpose of promoting empowerment and positive feelings towards child rearing may become possible in the future based on the results of this study.

\section{Acknowledgements}

We would like to express our deepest gratitude to all the subjects and staff of the facilities at which this research was conducted for their cooperation in this study. This study was supported by a Grant-in-Aid for Young Scientists (B) (No. 24792517).

\section{Disclosure}

The authors declare that they have no competing interests.

\section{References}

[1] Okada, K. (2006) The History of Children with Severe Motor and Intellectual Disabilities. In: Asakura, T., Ed., Total Care of Children with Severe Motor and Intellectual Disabilities, Herusu Shuppan , Tokyo, 15-20. (In Japanese)

[2] Geeter, K.I., Poppes, P. and Vlaskamp, C. (2002) Parents as Experts: The Position of Parents of Children with Profound Multiple Disabilities. Child: Care, Health and Development, 28, 443-453. http://dx.doi.org/10.1046/j.1365-2214.2002.00294.X

[3] Kuno, N., Yamaguchi, K. and Morita, C. (2006) The Sense of Burden of Mothers with Severely Disabled Children at Home and the Related Factors. Journal of Japanese Society of Nursing Research, 29, 59-69. (In Japanese) http://www.jsnr.jp/test/search/docs/202905003.pdf

[4] Sugimoto, A., Nakamura, Y., Umeda, H., Akahane, E., Naijo, E. and Shibutani, H. (2009) The Characteristics of Family Function in Families with a Child with Disabilities: Research in A Prefecture. Journal of Japan Academy of Human Care Science, 2, 49-56. (In Japanese)

[5] Harden, J. (2005) Parenting a Young Person with Mental Health Problems: Temporal Disruption and Reconstruction. Sociology of Health \& Illness, 27, 351-371. http://dx.doi.org/10.1111/j.1467-9566.2005.00446.x http://onlinelibrary.wiley.com/doi/10.1111/j.1467-9566.2005.00446.x/epdf

[6] Sloper, P. and Turner S. (1993) Risk and Resistance Factors in the Adaptation of Parents of Children with Severe Physical Disability. Journal of Child Psychology and Psychiatry, 34, 167-188. http://dx.doi.org/10.1111/j.1469-7610.1993.tb00978.x

[7] King, G.A., Rosenbaum, P.L. and King, S.M. (1997) Evaluating Family-Centred Service Using a Measure of Parents' Perceptions. Child: Care, Health and Development, 23, 47-62. http://dx.doi.org/10.1046/j.1365-2214.1997.840840.x

[8] Walsh, T. and Lord, B. (2004) Client Satisfaction and Empowerment through Social Work Intervention. Social Work in Health Care, 38, 37-56. http://dx.doi.org/10.1300/J010v38n04_03

[9] Koren, P.E., DeChillo, N. and Friesen, B.J. (1992) Measuring Empowerment in Families Whose Children Have Emotional Disabilities: A Brief Questionnaire. Rehabilitation Psychology, 37, 305-321. http://dx.doi.org/10.1037/h0079106

[10] Segal, S.P., Silverman, C. and Temkin, T. (1995) Measuring Empowerment in Client-Run Self-Help Agencies. Community Mental Health Journal, 31, 215-227. http://dx.doi.org/10.1007/BF02188748

[11] Wakimizu, R., Fujioka, H., Furuya, K., Miyamoto, S., Ieshima, A. and Yoneyama, A. (2010) Development of the Jap- 
anese Version of the Family Empowerment Scale. Journal of Health and Welfare Statistics, 11, 33-41. (In Japanese)

[12] Herbert, R.J., Gagnon, A.J., Rennick, J.E. and O’Loughlin, J.L. (2009) A Systematic Review of Questionnaires Measuring Health-related Empowerment. Research and Theory for Nursing Practice, 23, 107-132.

[13] Ministry of Health, Labour and Welfare (2010) The $3^{\text {rd }}$ General Welfare Committee Documents. http://www.mhlw.go.jp/bunya/shougaihoken/sougoufukusi/2010/06/dl/0601-1d.pdf

[14] Hase, M. (2010) Development of a Questionnaire Concerning the Condition of Mothers of Children with Severe Motor and Intellectual Disabilities Who Live at Home. Journal of Severe Motor and Intellectual Disabilities, 35, 143-150. (In Japanese)

[15] Natsume, M., Ota, Y., Noda, T., Sato, T., Yamada, K, Hanatani, T., Kamata, M., Iwata, K., Inui, T. and Murata, H. (1999) The Social Readjustment Rating Scale for the Elderly. The Japanese Journal of Stress Sciences, 13, 222-229. (In Japanese)

[16] Ishikawa, R. (2007) The Stress and Social Support of Home Caregivers: A Health and Psychological Study. Kazamashobo, Tokyo. (In Japanese)

[17] Hirose, M., Okada, S. and Shirasawa, M. (2005) The Factors Related to Family Caregivers’ Positive Appraisal of Care. Journal of Health and Welfare Statistics, 52, 1-7. (In Japanese)

[18] Arai, Y., Tamiya, N. and Yano, E. (2003) The Short Version of the Japanese Version of the Zarit Caregiver Burden Interview (J-ZBI_8): Its Reliability and Validity. Japanese Journal of Geriatrics, 40, 497-503. (In Japanese) https://www.jstage.jst.go.jp/article/geriatrics1964/40/5/40_5_497/_pdf

[19] Kitazumi, E., Iwasaki, Y., Izumi, M. and Akiyama, K. (2007) The Role of Facilities for Children with Super Severe Motor and Intellectual Disabilities as a System of Support for Daily Living. Ryoushin no Tsudoi, 606, 2-18. (In Japanese)

[20] Ozawa, H., Kato, I., Ozaki, H., Ishizuka, T., Arimoto, K. and Kimiya, S. (2007) The Present Situation of Children with Psycho-Motor Disabilities and Their Parents. Official Journal of the Japanese Society of Child Neurology, 39, $279-282$. (In Japanese)

[21] Ministry of Health, Labour and Welfare (2013) The 2011 Fiscal Year National Health and Nutrition Survey. http://www.mhlw.go.jp/bunya/kenkou/eiyou/dl/h23-houkoku.pdf

[22] Hori, T. (2006) Lobbying Movements by Parents of Children with Severe Motor and Intellectual Disabilities during High Economic Growth and Their Background. Japanese Journal of Social Welfare, 47, 31-44. (In Japanese)

[23] Nachshen, J.S. and Minnes, P. (2005) Empowerment in Parents of School-aged Children with and without Developmental Disabilities. Journal of Intellectual Disability Research, 49, 889-904. http://dx.doi.org/10.1111/j.1365-2788.2005.00721.x

[24] Ozawa, H., Kimiya, S., Funahashi, M., Miyaji, S., Kurata, K., Tanuma, N., Tomita, S., Miyama, S., Shikura, K., Yamada, N., Uchiyama, K., Kurihara, E., Nakamura, Y. and Sasaki, M. (2010) The Present Situation of Children with Severe Motor and Intellectual Disabilities: Medical care-dependent Children and Their Parents in the Tama Area of Tokyo. The Journal of the Japan Pediatric Society, 114, 1892-1895. (In Japanese)

[25] Oshio, A., Nakaya, M., Kaneko, H. and Nagamine, S. (2002) Development and Validation of an Adolescent Resilience Scale. Japanese Journal of Counseling Science, 35, 57-65. (In Japanese)

[26] Zensho, M. (2006) A Study of Children with Severe Motor and Intellectual Disabilities and Their Family’s Home Care Needs and Social Supports. The Bulletin of Saitama Prefectural University, 7, 51-58. (In Japanese) http://ci.nii.ac.jp/els/110005001975.pdf?id=ART0008078095\&type=pdf\&lang=ip\&host=cinii\&order no=\&ppv type= 0\&lang_sw $=\& n o=1448194448 \& \mathrm{cp}=$

[27] Orr, R.R., Cameron, S.J. and Day, D.M. (1991) Coping with Stress in Families with Children Who Have Mental Retardation: An Evaluation of the Double ABCX Model. American Journal of Mental Retardation, 95, 444-450.

[28] Zimmerman, M.A. and Warschausky, S. (1998) Empowerment Theory for Rehabilitation Research: Conceptual and Methodological Issues. Rehabilitation Psychology, 43, 3-16. http://dx.doi.org/10.1037/0090-5550.43.1.3

\section{Appendix}

The questionnaire that was actually used in this study can be referred to in the following URL. (In Japanese) https://researchmap.jp/musrndur8-2070545/?action=multidatabase_action_main_filedownload\&download_flag= $\underline{1 \text { \&upload_id=99758\&metadata_id=170582 }}$ 